\title{
KARAKTERISTIK FRAKTUR MAKSILOFASIAL DI RSUP DR. M. DJAMIL PADANG TAHUN 2014-2016
}

\author{
Irma Oktavina Zulmi ${ }^{1}$, Rima Semiarty ${ }^{2}$, Angei Laura ${ }^{3}$ \\ ${ }^{1}$ Faculty of Dentistry Andalas University \\ ${ }^{2}$ Departemen of Oral Surgery Faculty of Dentistry Andalas University
}

\begin{abstract}
Maxillofacial fractures or facial fractures are discontinuity of the facial bone. Maxillofacial fractures are the most common cause traffic accidents. RSUP. M. Djamil is the main referral hospital in the city. That can be found at RSUP. DR. M. Djamil Padang. To determine the characteristics of maxillofacial fractures in RSUP. M. D jamil Padang in 2014- 2016.The type of this research is Obsevational Descriptive by using a retrospective design, there are 78 samples takenmfrom medical records. As for the sampling technique, we use simple random sampling. This study was conducted with a sample based on the data group maxillofacial fractures based on the type of fracture, the patient's age, gender, aetiology and treatment. Then, the tabulation and presentation of data using SPSS version 22.0. there are 78 patients from 350 patients who suffered maxillofacial fractures. The highest number of 27 patients $(34,6 \%)$ had multiple fractures, 61 patients (78,2\%) experienced by men, most in the age 11-20 years as many as 36 patients (46,2\%), the highest caused by traffic accident 75 patients (96,2\%), the most performed treatment was closed reduction 39 patients (50\%). Traffic accidents are the leading cause of maxillofacial fractures. Based on the type of fractures more patients suffered multiple fractures being experienced at the age of 11-20 years. The most performed treatment was closed reduction.
\end{abstract}

Keywords:Maxillofacial fractures, RSUP. Dr. M. Djamil Padang

Affiliasi penulis :1. RSUP. Dr. M. D.jamil Padang, 2. Satlantas POLRESTA Kota Padang.

Korespondensi:Irma Oktavina Zulmi, irmazulmi07@gmail.com, Telp: 08126762484

\section{PENDAHULUAN}

Penduduk Kota Padang mencapai jumlah 876.678 jiwa pada tahun 2013, meningkat sejumlah 22.342 jiwa dibandingkan tahun sebelumnya. Seiring dengan meningkatnya mobilitas penduduk, maka jumlah kendaraan bermotor ikut meningkat, sehingga resiko kecelakaan lalu lintas juga ikut meningkat. ${ }^{1,2}$ Data statistik WHO menunjukkan bahwa kecelakaan lalu lintas pada tahun 1998 menduduki peringkat ke-9 sebagai penyebab kematian di dunia. Diperkirakan pada tahun 2020, kecelakaan lalu lintas akan menjadi penyebab kematian ke-3 tertinggi di dunia di bawah penyakit jantung koroner dan depresi berat. $^{3}$

Ada banyak faktor yang menyebabkan fraktur maksilofasial, seperti kecelakaan lalu lintas, kecelakaan kerja, kecelakaan akibat olah raga, kecelakaan akibat peperangan, kekerasan individu. Tetapi penyebab terbanyak adalah kecelakaan lalu lintas. ${ }^{4,5}$ Menurut data dari Satlantas Polresta Kota Padang terdapat kurang lebih 1.467 kejadian selama kurun waktu 2014-2016, dimana korban yang meninggal dunia sebanyak 188 orang, korban yang mengalami luka berat 857 
orang dan korban dengan luka ringan 1.557 orang. Fraktur maksilofasial mempunyai banyak variasi antara lain fraktur mandibula, fraktur maksila, fraktur kompleks zigoma, fraktur dentoalveolar, fraktur nasal, dan fraktur multipel. Fraktur maksila terdiri atas fraktur le fort I, le fort II, dan le fort III

Fraktur mandibula terdiri dari fraktur simfisis, parasimfisis, korpus, sudut mandibula, ramus, koronoid dan kondilus. ${ }^{6}$ mendapatkan perhatian khusus dalam jumlah kasus yang terjadi dan penanganan yang telah dilakukan serta tingkat keberhasilan perawatan. Hal ini dapat menjadi acuan bagi dokter gigi khususnya bagian bidang Bedah Mulut untuk mengetahui karakteristik fraktur maksilofasial sehingga di masa mendatang dapat menentukan perawatan yang lebih baik pada kasus Fraktur Maksilofasial.

RSUP Dr.M. Djamil Padang lulus akreditasi rumah sakit Paripurna dari Komisi Akreditasi Rumah Sakit (KARS) sehingga telah memenuhi syarat menjadi rumah sakit negri kelas A berada di Padang milik Kementerian Kesehatan Republik Indonesia. Merupakan rumah sakit rujukan untuk wilayah Sumatera Barat. Selain itu RSUP. M. Djamil juga merupakan salah satu rumah sakit pendidikan di Kota padang. ${ }^{7}$ Menurut data dari bagian rekam medik di RSUP Dr.M. Djamil Padang fraktur maksilofasial berjumlah 213 kasus dimana pada tahun 2014 sebanyak 114 kasus, tahun 2015 sebanyak 78 kasus, dan tahun 2016 sebanyak 21 kasus. Pada peneliti sebelumnya di Rumah Sakit Hasan Sadikin Bandung terdapat sebanyak 354 orang pasien yang mengalami fraktur maksilofasial dari tahun 2009-2011.8 Selama ini penelitian tentang karakteristik fraktur maksilofasial di RSUP Dr. M. Djamil Padang belum pernah dilakukan, karena itu penulis merasa perlu untuk meneliti karakteristik fraktur maksilofasial tahun 2014 hingga tahun 2016.

\section{METODE}

Penelitian ini merupakan penelitian observasional deskriptif yang dilakukan di bagian rekam medik RSUP. Dr. M. Djamil Padang pada bulan Januari-Maret 2017. Sampel penelitian ini adalah 78 pasien dengan kasus fraktur maksilofasial di RSUP. Dr. M. Djamil Padang tahun 20142016.

Teknik pengambilan sampel pada penelitian ini adalah simple random sampling dengan kriteria inklusi yaitu semua data sekunder rekam medis dengan diagnosis fraktur maksilofasial di RSUP. Dr. M. Djamil Padang pada tahun 2014 sampai 2016. Berdasarkan tipe fraktur, usia, jenis kelamin, etiologi, terapi yang diterima dan dikelompokkan bagian Bedah Mulut, THT, Brdah Umum dan Bedah Plastik. Kriteri ekslusi adalah semua data sekunder yang tidak di eksklusikan. 


\section{HASIL}

Pada penelitian ini diperoleh data kasus fraktur maksilofasial di RSUP. Dr. M. Djamil Padang pada tahun 2014 hingga 2016 sebanyak 350 kasus dengan sampel 78 kasus.

\begin{tabular}{|c|c|c|}
\hline $\begin{array}{l}\text { Karakteristik } \\
\text { Responden }\end{array}$ & Jumlah & Persentase \\
\hline \multicolumn{3}{|l|}{ Jenis Kelamin } \\
\hline Laki-laki & 61 & 78.2 \\
\hline Perempuan & 17 & 21.8 \\
\hline Total & 78 & 100.0 \\
\hline \multicolumn{3}{|l|}{ Umur } \\
\hline $0-10 \mathrm{TH}$ & 3 & 3.8 \\
\hline $11-20 \mathrm{TH}$ & 36 & 46.2 \\
\hline 21-30TH & 18 & 23.1 \\
\hline 31-4OTH & 10 & 12.8 \\
\hline $41-50 \mathrm{TH}$ & 6 & 7.7 \\
\hline 51-60TH & $i^{4}$ & 5.1 \\
\hline$>60 T H$ & 1 & 1.3 \\
\hline Total & 78 & 100.0 \\
\hline
\end{tabular}

Pada penelitian ini terdapat sebanyak 78 data rekam medik pasien fraktur maksilofasial yang dijadikan sampel. Pasien laki-laki sebanyak 61 orang $(78,2 \%)$ dan pasien perempuan sebanyak 17 orang $(21,8 \%)$.

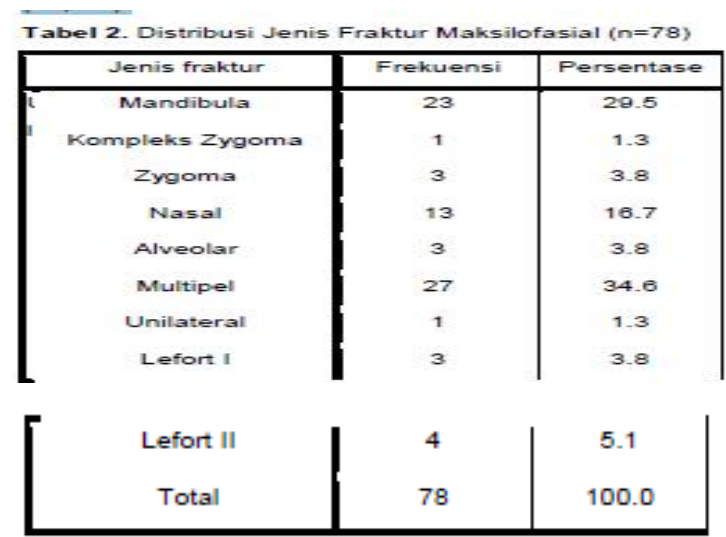

\section{Berdasarkan jenis fraktur} didapatkan fraktur multipel lebih sering terjadi $(34,6 \%)$ dibandingkan dengan fraktur yang lainnya, fraktur mandibula menempati urutan kedua sebanyak 23 pasien $(29,5 \%)$.

Tabel 3. Distribusi Fraktur Multipel $(n=78)$

\begin{tabular}{|c|c|c|}
\hline Jenis Fraktur & Frekuensi & Persentase \\
\hline Mandibula & 7 & 22.6 \\
Zygoma & 7 & 22.6 \\
Nasal & 4 & 12.9 \\
Lefort I & 9 & 29.0 \\
Lefort II & 2 & 6.5 \\
Alveolar & 2 & 6.5 \\
Total & 31 & 100.0 \\
\hline
\end{tabular}

Tabel distribusi fraktur multipel didapatkan pasien fraktur le fort I yang sering terjadi sebanyak 9 pasien (29\%) diikuti dengan fraktur mandibula dan zygoma sebanyak 7 pasien $(22,6 \%)$.

Tabel 4. Distribusi Etiologi Fraktur Maksilofasial $(\mathrm{n}=78)$

Tabel 4. Distribusi Etiologi Fraktur Maksilofasial $(n=78)$

\begin{tabular}{|c|c|c|}
\hline Etiologi & Frekuensi & Persentasi \\
\hline Kecelakaan Lalu Lintas & 75 & 96.2 \\
Kecelakaan Kerja & 1 & 1.3 \\
Terjatuh & 2 & 2.6 \\
Total & 78 & 100.0 \\
\hline
\end{tabular}

Berdasarkan etiologi fraktur ada beberapa faktor yang dapat menyebabkan terjadinya fraktur maksilofasial yaitu kecelakaan lalu lintas sebanyak 75 pasien $(96,2 \%)$. 
Tabel 5. Distribusi Berdasarkan Bagian Rawatan $(n=78)$

\begin{tabular}{|c|c|c|}
\hline Bagian & Frekuensi & Persentase \\
\hline THT & 25 & 32.1 \\
BM & 3 & 3.8 \\
\hline BP & 43 & 55.1 \\
BU & 7 & 9.0 \\
Total & 78 & 100.0 \\
\hline
\end{tabular}

Fraktur maksilofasial ditangani oleh beberapa tenaga spesialis yaitu THT, Bedah Mulut, Bedah Platik dan Bedah Umum. Spesialis yang paling banyak menangani pasien fraktur maksilofasial berdasarkan data ini adalah spesialis Bedah Plastik sebanyak 43 pasien $(55,1 \%)$, diikiti dengan THT sebanyak 25 pasien $(32,1 \%)$, Bedah Umum sebanyak 7 pasien (9\%) dan Bedah Mulut 3 pasien $(3,8 \%)$.

Tabel 6. Distribusi Berdasarkan Terapi Fraktur Maksilofasial ( $\mathrm{n}=78)$

\begin{tabular}{|c|c|c|}
\hline Terapi & Frekuensi & Persentase \\
\hline Terbuka & 29 & 37.2 \\
Tertutup & 39 & 50.0 \\
Terbuka dan Tertutup & 4 & 5.1 \\
Menolak Tindakan & 3 & 3.8 \\
Observasi & 2 & 2.6 \\
Meninggal & 1 & 1.3 \\
Total & 78 & 100.0 \\
\hline
\end{tabular}

Terapi yang diterima pasien pada tabel diatas adalah reduksi terbuka, reduksi tertutup dan gabungan. Terapi yang paling banyak diterima pasien adalah reduksi tertutup 39 pasien (50\%), diikuti dengan terapi terbuka sebanyak 29 pasien $(37,2 \%)$.

\section{PEMBAHASAN}

Jumlah distribusi penderita fraktur maksilofasial berdasarkan jenis kelamin sebanyak 78 sampel rekam medik. Didapatkan 61 pasien lak-laki lebih banyak dari pasien perempuan dari keseluruhan penderita fraktur maksilofasial. Hasil yang diperoleh sama dengan penelitian Ajike dan kawan-kawan yang menyatakan bahwa laki-laki lebih tinggi frekuensinya dibandingkan dengan perempuan. Hasil penelitian diperkuat dari data penelitian Jose Luiz Rodrigues Leles dan kawankawan melaporkan bahwa laki-laki mempunyai prevalensi yang lebih tinggi dibandingkan perempuan dalam insidensi fraktur maksilofasial, dengan rasio 3:1. Sejalan dengan tingkat insidensi kecelakaan lalu lintas yang lebih banyak dialami lakilaki karena jumlah penggunaan kendaraan bermotor lebih banyak laki-laki. ${ }^{9,10}$

Menurut kelompok usia hasil penelitian ini menunjukkan bahwa kelompok usia 11-20 tahun merupakan peringkat teratas, ini berarti fraktur maksilofasial terjadi pada rentang usia remaja. kemudian diperingkat kedua yaitu pada usia 21-30 tahun. Hasil yang diperoleh sama dengan hasil penelitian Angei LD dan kawan-kawan menyatakan bahwa fraktur maksilofasial sering terjadi pada umur remaja 11-20 tahun. hal ini kemungkinan disebabkan oleh kebebasan mengendarai sepeda motor oleh orang tua pasien.7 
Sedangkan pada penelitian Amir Dibaie dan kawan-kawan bahwa fraktur maksilofasial lebih banyak terjadi pada rentang usia 21-30 tahun. Tidak jauh berbeda dengan penelitian Syed AS dan kawan-kawan juga lebih banyak terjadi pada usia produktif 21-30 tahun dan usia 11-20 tahun menempati posisi kedua. Ini dikarenakan bahwa orang-orang yang berada pada rentang usia 21-30 tahun lebih banyak mengambil kegiatan ataupun aktifitas diluar rumah dalam kehidupan sehari-hari. ${ }^{11,12}$

Berdasarkan hasil penelitian jenis fraktur, fraktur yang sangat tinggi angka kejadiannya adalah multipel. Dilihat dari distribusi fraktur multipel yang paling banyak terjadi adalah lefort I. Berbeda dengan penelitian sebelumnya menunjukkan bahwa fraktur multipel paling tinggi fraktur mandibula (parasimfisis) sebanyak 38 pasien dari 354 sampel. Diikuti dengan fraktur mandibula. Hal ini berbeda dengan penelitian sebelumnya bahwa fraktur mandibula merupakan fraktur yang banyak terjadi akibat kecelakaan lalu lintas pada pengendara sepeda motor, dengan masing-masing persentase sebesar $46,3 \%, 51 \%$ dan $72,8 \%$. Di instalasi gawat darurat yang terletak dikota besar, setiap harinya fraktur mandibula merupakan kejadian yang sering terlihat. Urutan selanjutnya diikuti oleh fraktur nasal, fraktur unilateral, fraktur le fort I dan le fort II, fraktur zygoma dan alveolar, kompleks zygoma dan fraktur le fort III pada penelitian ini tidak ditemukan. Pada penelitian ini didapatkan fraktur multipel lebih banyak dari fraktur mandibula. ${ }^{6,7,13}$

Berdasarkan etiologi fraktur maksilofasial pada penelitian ini yang terbanyak adalah kecelakaan lalu lintas, diikuti dengan pasien yang terjatuh dan kecelakaan kerja. Hal serupa ditemukan di penelitian lain yang mengemukakan kecelakaan lalu lintas merupakan etiologi tersering di brazil. Hasil penelitian ini membenarkan asumsi mengenai fraktur maksilofasial paling banyak disebabkan kecelakaan lalu lintas. ${ }^{14}$

Dilihat dari bagian rawatan/spesialisasi yang menangani fraktur maksilofasial adalah THT, Bedah Mulut, Bedah Plastik dan Bedah Umum yang paling banyak menangani fraktur maksilofasial adalah spesialisasi Bedah Plastik, diikuti dengan THT, Bedah Umum dan Bedah Mulut. Menurut Benni Raymond spesialis Bedah Plastik di RSUP. Dr. M. Djamil Padang bahwa dalam penatalaksanaan fraktur maksilofasial sesuai dengan SOP (Standar Operasional) yang mengacu ke standar pelayanan medis bedah plastik yang diterbitkan oleh Kolegium Ilmu Bedah Plastik. Sarana dan prasarana di bagian bedah plastik masih saja ada kekurangan. Dalam kurun waktu 2014-2015, 
ketersediaan alat operasi masih terbatas sehingga masih sering memakai alat terutama (hand drill) yang dibawa sendiri (tetap disterilkan sesuai SOP). Untuk IMPLANT (plate, screw, arch bar, wire) di proyeksikan penggunaan alat setiap 6 bulan. Kendala yang sering terjadi adalah jika ada lonjakan kasus maka implant akan cepat habis dan permintaan penyediaan implant tambahan butuh prosedur yang cukup rumit dan memakan waktu, sehingga penanganan pasien terkendala. Ketersediaan implant dan fungsi alat selalu diperiksa sebelum melakukan operasi untuk menghindari kendala saat melakukan operasi. Bedah mulut yang paling sedikit menangani fraktur maksilofasial di RSUP Dr. M. Djamil Padang Tahun 2014-2016 dikarenakan spesialis Bedah Mulut tidak ada pada tahun 2016.

Pasien yang mengalami fraktur maksilofasial pada penelitian ini paling banyak adalah terapi reduksi tertutup, diikuti dengan terapi terbuka dan gabungan. Penelitian ini sama dengan penelitian Syed AS, bahwa terapi reduksi tertutup paling banyak diberikan.12 Diperkuat oleh penelitian Hamad Ebrahim Al Ahmed, DDS dan kawan-kawan dimana perawatan yang paling banyak diberikan adalah reduksi tertutup (67\%). Ini dikarenakan keterbatasan plat dan sekrup yang disediakan oleh rumah sakit tempat penelitian melakukan penelitian (Al
Qassimi Hospital di Sharjah).15 Berbeda dengan penelitian Angei LD dan kawankawan menunjukkan terapi reduksi terbuka lebih tinggi dibandingkan reduksi tertutup. Terdapat 3 dari 78 sampel pasien menolak tindakan mungkin ini disebabkan karena pasien pindah perawatan kerumah sakit lain, tidak mampu memenuhi biaya perawatan atau karena kebiasaan masyarakat untuk memperbaiki fraktur kepada tukang urut.

\section{KEPUSTAKAAN}

1. Kementrian Perhubungan Sulawesi Selatan. Profil dan kinerja perhubungan darat Provinsi Sulawesi Selatan 2013. Sulawesi Selatan: Dishub, 2013: p. 10-23. Available on: bagren@hubdat.web.id

2. BPS Kota Padang. Padang dalam angka 2014; 2014 p.61. Available on: http://bappeda.padang.go.id/up/download/0 4122014084307Padang-Dalam-Angka2013-upload.pdf

3. Riandini LI, Susanti R, Yanis A. Gambaran luka korban kecelakaan lalu lintas yang dilakukan pemeriksaan di RSUP. Dr.M. Djamil Padang. J FK UNAND. 502-503

4. Bailey H. Ilmu bedah gawat darurat Ed. II. Yogyakarta: Gajah Mada University Press; 1992.

5. Fonseca RJ, Walker RV. Oral and maxillofacial trauma. Ed. 2, Vol.2 USA:W.B.Saunders Company; 2005.

6. Budiharja AS, Rahmat M. Trauma oral dan maksilofasial. Juwono L: Editor. Jakarta: EGC; 2011: p.33-171. 
7. Angei Laura D, Endang S, Fathurrahman. Characteristic of Maxillofacial Fractures In Hasan Sadikin Hospital Whitin Period 2009-2011. J Oral Maxillofacial Surg. 2012

Okt;(3): 93-126

8. RSUP M. Djamil Padang, (n.d).availabl on:http://www.rsdjamil.co.id/detailpost/rsu p-dr-m-djamil-padang-lulus-akreditasirumah-sakit-tingkat-paripurna-dari-kars

9. Ajike SO, Adebayo ET, Amanyewe Eu. An Epidemiologic Survey Of Maxillofacial Fractures and Concomitant Injuries In Kaduna. Nigeria. Nigeria $J$ of Surgical Research ; 2005 : P. 251-55.

10. Leles JLR, Santos EJ, Jorge FD, Silva ET, Leles CR. Risk Factors For Maxillofacial Injuries In A Brazillian Emergency Hospital Sample. J Appl Oral Sci ; 2010: 18(1): P.9-23

11. Dibaie A, Raissian S, Ghafarzadeh S. Evaluation Of Maxillofacial Traumatic Injuries Of Forensic
1. Medical Center Of Ahwaz, Iran in 2005. Pak J Med Sci 2009: 25(1): 79-82

12. Syed A.S, Zahid Q.B, Tahir U.K, Muhammad Y, Muhammad R, Syed F.S. The Pattern of Maxillofacial Trauma and its Management, Pakistan. J of Dent,Oral Disorders and Therapy ; 2012; P.1-6

13. Baumann A, Troulis MJ, Kaban LB. Facial traumaII : dentoalveolar injuries and mandibular fractures. In: Kaban LB, Troulis MJ, Pediatric oral and maxillofacial surgery. USA: Elsevier Science; 2004 : p.446.

14. Maliska M. Analysis of 185 Maxillofacial Fractures In State Of Santa Catarina Brazil, Brazil Oral Res ; 2009

15. Al Ahmed H.E, Jaber M.A, Salem H, Karas M. The pattern of maxillofacial fractures in Sharjah, United Arab Emirates: a review of 230 cases. $2004 ; 98: 166-170$ 